\title{
Comparative analysis of creative process methodologies for products development - a case study of the large scale toys production
}

\author{
Lucas Felipe Haeser ${ }^{a}$, Renato Viziolib, Paulo Carlos Kaminski ${ }^{b}$ \\ oThe Marketing Store Worldwide \\ Universidade de São Paulo \\ e-mails: lucashaeser@gmail.com; rvizioli@usp.br; pckamins@usp.br
}

\begin{abstract}
The speed the market demands for new products development and launching not only creates challenges amongst the technical, productive and operational aspects, but also in product conception. This article explores a case in which the conception becomes even more critical: the development of promotional toys - such as the ones commonly sold inside Easter eggs - those seasonality, large scale, safety criteria and visual appeal, mentioning just a few characteristics, make the creative process a crucial role in the cycle of product development. Therefore, the following creativity tools are analyzed: design thinking, brainstorming, brainwriting, post-up and individual creation. In addition, a comparative practical study is performed using similar evaluation criteria in order to identify the best techniques for each type of need.
\end{abstract}

Keywords: generation of ideas, creativity, toys.

\section{Development of products in the industry of promotional toys inside Easter eggs}

Amongst the most important dates of Brazilian retail sales, Easter just stays behind Christmas and Mother's Day in sales volume (PRADO, 2014). According to the Brazilian Cocoa, Chocolate, Peanut and Candies Manufacturers Association (ASSOCIAÇÃO..., 2014), Brazil is the world's third largest chocolate consuming market, just behind the United States and Germany. Eighty millions of chocolate Easter eggs are made available for the consumers, representing approximately eighteen thousand tons of the product. Part of this market is composed of tens of promotional toys, which are given as gifts inside or outside Easter eggs. Of the uncountable number of ideas for products generated in every Easter, only a few of them become products and are made available for the consumer. New ideas are required every year, all of them meeting certain specific safety rules and according to the policy and guidelines of the corresponding licensor. The challenge is, inside this specific universe, to find which are the best forms of generating a great amount of innovative ideas, in a repetitive and fast way.

\section{Creativity in the development of promotional toys inside Easter eggs}

The scenario studied is highly demanding regarding the safety, as it involves child consumers as well as the food market. Major companies in this sector, either by their own initiative or due to governmental requirements, surround themselves with standards and restrictions to protect this market and to ensure that their products are safe for all ages. These standards impose a series of obstacles that, many times, hamper the creation process of creation professionals, who have to generate ideas of new products.

On the other hand, the restrictions act to guide the creative process. With no limitations of safety, quality, deadline time, cost, in addition to restrictions imposed by licensors and customers' specific requests, the creation of new toys would be chaotic and have no direction. Lehrer (2012b) states that the imagination is enhanced and awaken by the restrictions and this is what makes the professionals seek innovative solutions. As an example, he mentions the poets, who force themselves to search for non-obvious words when limiting to the formats with rhymed formats. Deadlines and limitations impose discipline for each project and, many times, this is what is actually seen.

\section{The market of promotional toys in Easter eggs}

In this market, the customer is the manufacturer of chocolate eggs, who seeks companies specialized in products to create and to develop its gifts. Alongside the customer there is the licensor, which are companies that own the rights of use of famous characters in movies and cartoons. These characters are desired by children. Both the 
customer and the licensor have their own rules. For example, Premiums' Manual of Specifications of one of the country's largest food companies prohibits, among others, flying toys, latex balloons, balls smaller than $44 \mathrm{~mm}$, weapon-like toys, disc-shaped toys smaller than $38 \mathrm{~mm}$, food-like items, flotation buoys, items with mercury-containing batteries, decals or sticky tattoos.

In addition, the company creating and manufacturing the gifts, which is also a multinational corporation as the customer, has internal rules that require that the toys are approved for all ages, prohibiting the presence of small or fragile parts, which can be swallowed by children. This is an especially high risk in children under three years. This is extremely important as it addresses a product that is sold with food.

There are restrictions from the licensor that can be as varied as possible, added to the security restrictions imposed by the customer and by the company. Some known licenses, such as Marvel/Disney's Spider-Man, for example, do not allow Easter toys to: be dolls, imitate the character's web shooters, or be used as role-play, i.e., the child cannot use the product to pretend to be the character, which also excludes masks and costumes. Other criteria require that the product contains two or three characters at the same time, or that they express vague concepts as "transformation" or "cuteness".

This scenario is surrounded by the most diverse requirements coming from several participants of the process, which makes the creative process difficult and at the same time guides it. There are also long term external threats, coming from the government and some non-governmental organizations, which understand that even children-directed advertising should be abolished. It would include the prohibition of toys linked to food that can harm the health, if consumed in excess.

\subsection{The consumer of promotional toys in Easter eggs}

The consumer can be classified as the user and the purchaser, respectively the children and, in general, the parents. Each one of them has different concerns regarding the Easter egg, which implies in a new series of restrictions and new guidelines for the creation. The child wants to know whether the product can entertain him and which tricks it allows him to invent. Moreover, the child must identify the values from the respective character that pleases him. On the other hand, parents are concerned whether the values transmitted by the product are positive for their children, whether it will please them, or whether the product has any risk for their health or integrity. Figure 1 presents a summary of the main variables described here, which guide the creative process of promotional toys in Easter eggs.

A product that displeases the consumer or teaches a questionable value is at risk of being removed from the shelves or hanging apparatus, as in the case of the egg of a manufacturer accused by Procon of Rio De Janeiro of encouraging the practice of bullying by suggesting the consumer should "customize the packing with stickers and screw his friend" (FOLHA DE SÃO PAULO, 2014).

\subsection{Technical definitions for the product}

Promotional toys in Easter eggs, as other products, observe numerous standards, in order to meet quality and safety criteria, among others. There are tests defined by Mercosul, Standard number 300 of 2004 (ASSOCIAÇÃO..., 2011) and by the International Organization for Standardization, Standard 8124-1 of 2012 (INTERNATIONAL..., 2012). In the cycle of product development, this step is called design evaluation. The toy is submitted to mechanical, microbiological, impact or drop testing, bite test, torsion, traction, compression or bend tests, flammability testing, detection of heavy metals and migration of odor, especially as it addresses a product that is in contact with food. The toy and its smaller parts must be submitted to other tests in specific cylinders for verification of small parts, which ensures that these parts are not stuck in the throat of a child.

All tests and standards - when already considered from the conception of the idea - work as restrictions that guide the creative process.

\section{Tools for creativity}

The analysis of several tools of creativity is proposed as the form of addressing the variables described (Figure 1), which are to be included in the process of product

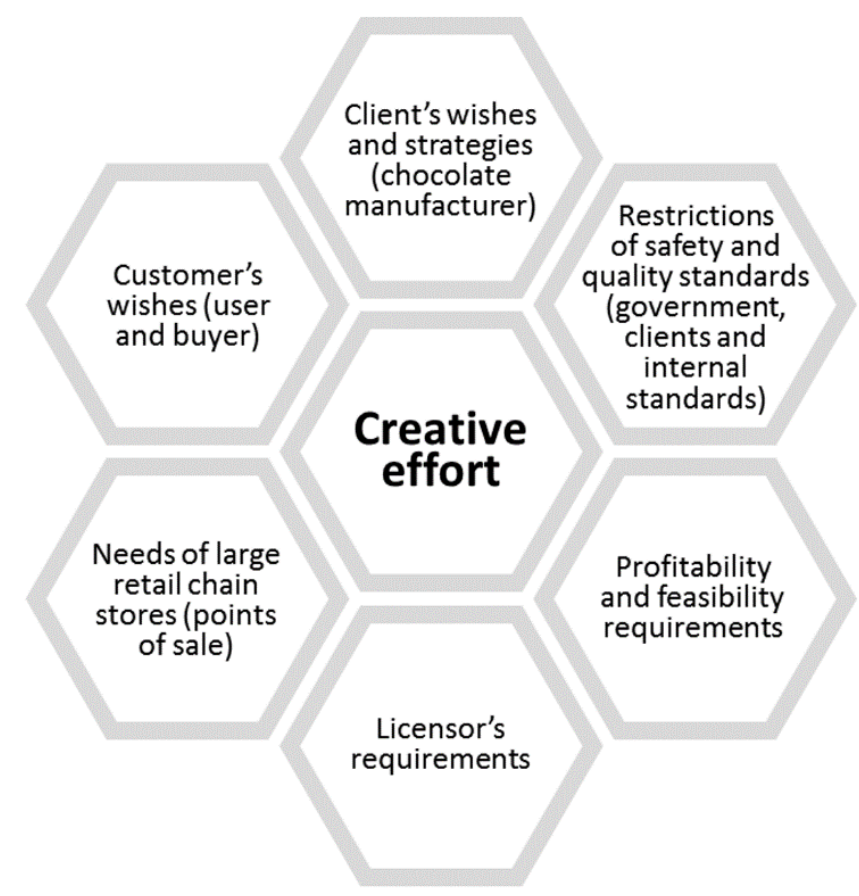

Figure 1. Incident variables in the creative effort of promotional toys in Easter eggs. 
development, in order to determine which of them is more adequate to this scenario. According to Amabile (1998), creativity is formed by three basic components: expertise, abilities of creative thought and motivation. A combination of environment, challenge, specific knowledge, freedom, resources and incentive is required to nourish the creativity and to promote the innovation.

Other authors suggest increasing the probability of random meetings and searching to escape from the comfort zone to generate innovative ideas, as reported by Frans Johansson:

"... The best chance for innovation is in the Intersection. In it we do not have only a bigger chance to find extraordinary combinations of ideas: we will find much more of them.... The intersection represents a place that drastically increases the possibilities of uncommon combinations to occur."(JOHANSSON, 2008, p. 42)

The author calls intersection any junction between what he calls fields. The fields are areas of the knowledge and can be as diverse as academic education, area of work, hobbies, sport practices, knowledge on poetry, tapestry etc. When one seeks to cross apparently disconnected areas of the knowledge on purpose, many times the result are innovative ideas.

According to Puccio (2013), creativity is a life skill, which arose as an evolutionary trace to oppose conformity, an ability that allows the collaboration among human beings, generating comfort and saving efforts for not excessively demanding the brain.

Several tools have been created throughout the years, seeking for innovation and creativity. These tools use many of these academic concepts and, theoretically, facilitate the process of generating new ideas. The most used tools by product designers and that are best suited for this specific case were selected amongst the many tools available for generation of ideas.

\subsection{Brainstorming}

The term brainstorming appeared in the 1950s and was popularized by Alex Faickney Osborn, writer and co-founder of BBDO advertising agency. The concept, currently established and widely spread out, is used in the most diverse sectors when a new idea must to be generated, either be the name of a new product or a specific solution for an engineering problem.

The concept of brainstorming is different from an ordinary meeting for generation of ideas especially by an agreement among the participants that consists of removing temporarily any criticism. It means creating a space, at least in theory, exempt of any judgment of value, in which there is no evaluation of the ideas, either positive or negative. The simple technique allows the participants to feel safe to speak openly and to participate without the fear to seem ridicule. According to Swiss philosopher Alain de Botton: "The fear of saying something stupid (which stupid people never have) has censored far more good ideas than bad ones." (BOTTOM, 2014).

The process proposed by brainstorming transforms the problem of an individual into the problem of a group, which in a safe space can generate a larger amount of options than would be individually possible. Having a larger amount of options increases the probability of at least one of the ideas meeting all the requirements of a project or solving the problem.

Currently, brainstorming technique is receiving a series of criticisms. Cain (2012) advocates that individuals working alone produce ideas in larger amount and of better quality than groups, especially when the group becomes very large. Such criticisms are based on researches made since the 1950s, as pointed by Lehrer (2014a) when describing comparative experiments between brainstorming and the sum of individual creation techniques. According to the author, results with higher quality and in larger amount can be obtained through the individual creation.

Despite the most recent criticisms, brainstorming is in fact still widely used, especially in product design and advertising agencies. In the market studied, the methodology is frequently used by designers and engineers. In practice, the constant use of brainstorming works as a way to train the professionals to accept ideas that confront their own ones, and teaches the habit of tolerance towards who thinks differently.

The playful side can be found in many of the creativity tools, either in the form of plays or not. According to the philosopher Huizinga (2001), play is any event that is always limited to a certain space and time, a "sacred place", material or imaginary, with its own rules that must be obeyed:

"The arena, the card-table, the magic circle, the temple, the stage, the screen, the tennis court, the court of justice, etc., are all in form and function play-grounds, i.e. forbidden spots, isolated, hedged round, hallowed, within which special rules obtain. All are temporary worlds within the ordinary world" (HUIZINGA, 2001, p. 13)

In Huizinga's terms, brainstorming per se can be considered a type of play, as it consists of space with specific rules (where criticizing is not allowed, for example). However, some tools use the playful side in a more literal way, trying through the play to extrovert people involved in order to allow a larger participation and, therefore, obtain a larger number of ideas.

Brown (2008) is one of the advocates of play as a generating element of creativity. For Brown, play in the daily routine helps to find more creative solutions.

The environmental safety is also pointed as an important factor in creativity by Halvorson (2015). For 
her "When you are in power, you can be more innovative because you feel more comfortable and secure, and less sensitive to or constrained by what other people think of you."(HALVORSON, 2013)

One of the best known playful techniques is the Six Thinking Hats, idealized by the author and researcher Edward De Bono Group (2008), inventor of the lateral thought, which proposes the solution of problems through indirect and creative approaches. The Six-Hats technique invites to use six different points of view when addressing a problem and has as advantage the possibility of being used with no need for a group: the white hat to observe the problem looking only at the facts; the yellow one to look only at the positive side and optimistically; the red one proposes to face the idea using only feelings, leaving reason out; the green one is the hat of the creativity, where it is possible to modify the idea; the blue one is the control mechanism that analyzes the idea as a whole; and the black hat, preferentially left to the end, proposes criticizing the idea hardly.

Others techniques explore the playful side more literally. Such is the technique proposed by the authors the Gray, Brown and Macanufo (2012), who propose a series of corporate games that stimulate the innovation. All the proposed plays follow a series of ten essentials:

1. Opening and Closing: it consists of keeping apart the moments of having divergent ideas and the moment of making decisions;

2. Fire Starting: the ability to ask provocative and at the same time focused questions, which direct to the desired path;

3. Artifacts: using tangible objects that keep information, such as post-it notes and pens;

4. Node Generation: reports and stories that must be generated by the participants;

5. Meaningful Space: the "board" of the game and the specific rules;

6. Sketching and Model Making: bringing the ideas to the visual field;

7. Randomness, Reversal and Reframing: shuffling and reorganizing ideas seeking to find relationships among them;

8. Improvisation: the inclusion of unexpected elements for the exploration of the ideas;

9. Selection: a moment of convergence, discarding or prioritization of the best ideas;

10. Try Something New: remaining open to modify the game, always having the initial objective in mind.
The main benefit of most of the playful tools is to bring freedom so that the ideas appear. By removing the rigidity and the seriousness of a meeting, a real problem that presents the commitment of finding a feasible is transformed into an interesting challenge. With a set of rules and an air of informality, the play equalizes the hierarchic levels and works as a facilitator, which is important especially if people do not know themselves or are not familiar to the others.

For this article, Post-up and Brainwriting - Development of Ideas tools, further detailed below were selected among the plays proposed by the authors.

\subsection{Brainwriting}

Brainwriting proposes everybody to remain silent and write in a paper all the ideas that come to mind, without judgments or filters. After a determined period of time, the papers are exchanged and another person must continue completing the colleague's list, still in silence, considering the previous ideas as inspiration. A variation of the process proposes transforming the list into paper airplanes and launching these to another participant, which adds an even more playful element to the methodology.

\subsection{Post-up}

Analogously to Brainswriting, Post-Up proposes a silent meeting. However, every person writes an idea in each post-it note instead of a list of ideas. Then, after a determined period of time, everybody sticks his/her ideas on a board or wall and shares his/her reasoning with the others. Following everybody's deliberations and the addition of new ideas generated during the conversation, a mental map must be organized containing all post-it notes, reorganizing, grouping and separating ideas and concepts into something visual that makes sense in the problem proposed.

\subsection{Design thinking}

The term Design Thinking was popularized by IDEO's president, Brown (2009) and currently is a tool widely used for resolution of problems in the most diverse businesses. A team seeking to generate innovative ideas must transit between what Brown calls three spaces of innovation: the space of inspiration, ideation and implementation. Design Thinking is an exploratory process, and walking through these three spaces must occur in a nonlinear form.

Another essential point of Design Thinking is the separation of the creative process in divergent thought and convergent thought. The technique is a methodology that organizes the process of generating ideas in two distinct time periods: the divergent one, in which generating the largest number of possible options is required, and the convergent one, in which it must be decided among the ideas to select the most pertinent ones. The second part of the process is a very important analytical part that has always been widely 
used to decide among a set of options. However, what differentiates the tool is the previous moment, the one to generate these options, and not only from the preexisting ones.

This separation ensures an advantage in relation to the competitors, as instead of starting from the same options known by everybody, the process generates new options the competitors probably do not consider.

Design Thinking starts from the assumption that any professional, and not only designers, can and must have innovative ideas, and that the hierarchy or the position must not be taken into account when analyzing an idea. Brown also advocates an "attitude of experimentation" that must permeate the whole organizational ecosystem of a company, and that a creative environment must assume risks.

In an organization that encourages experimentation, there will be projects destined to go nowhere and still others that the keepers of institutional memory prefer not to talk about, but:

"... To view such initiatives as "wasteful," "inefficient," or "redundant" may be a symptom of a culture focused on efficiency over innovation and a company at risk of collapsing into a downward spiral of incrementalism.”(BROWN, 2009, p. 67)

Visual thought is a very important factor in Design Thinking. Brown advocates the use of drawing pictures and mental maps to assist in the visualization of a problem, in addition to the use of post-it notes to easily pool ideas and change their place, especially when going from the divergent phase to the convergent one.

The concepts presented by Brown serve as basis for a series of other creativity tools. For instance, a strong similarity can be identified between Brown's technique of divergent and convergent thought and the essential of Opening and Closing found in Gray, Brown and Macanufo (2012). Despite this, Design Thinking is not exempt of criticisms. Nussbaum (2011), formerly a strong advocate of the idea, argues that in practice the positive results of Design Thinking do not overcome its failures. Nussbaum advocates a movement toward the lack of ready formulae and the theory of Creative Intelligence, which he defines as "the ability to frame problems in new ways and to make original solutions". The designer and author Jeffrey Tjendra (2014) advocates a similar idea. He believes that Design Thinking will suffer exactly due to its large repercussion. According to Tjendra, "organizations desire creativity but have difficulty of accepting the fuzziness, messiness, abstractness, and obscurity that come along with it."

Design Thinking, as well as Brainstorming, is also used in the creation of promotional toys, and its concepts are used in research.

\section{Case study}

The research proposes to analyze part of the tools previously displayed in the light of the scenario presented, which is the creation of toys given as gifts with Easter eggs. Thus, different groups of people with diverse ages and professions were selected, and the same specific problem was presented for each one of them in a quite simplified manner: generating ideas of low cost products, using Turma da Mônica's license, which are attractive to three to six years old boys and girls, and at the same time pleasing young adults who have grown up reading comic books created by Mauricio de Sousa. Afterwards, the results were compared using quantity and quality criteria for ideas generated in each one of the tools tested.

\subsection{Comparative analysis of the tools}

The techniques that make more sense at the beginning of a project, during the initial generation of concepts, were select amongst those presented here. These were Brainstorming, Brainwriting, Post-up, Design Thinking and what was called individual creation for this purpose, in order to evaluate the statements mainly by Cain (2012), who claims that individuals produce better ideas alone than in group.

\subsection{Methodology}

The group selection was made using the criteria of heterogeneity, always varying ages and genders, and always with groups with three different persons. No professional of the area was enrolled in the groups and no overlapping of participants in more than a group occurred.

A scoring system was created in order to evaluate the quality of the ideas presented, generating a final score for each product concept. Each idea was evaluated through the following five items (Table 1): relevance, feasibility, desirability, safety and estimated price, observing the requirements and restrictions illustrated in Figure 1. There is a series of questions that must be answered for each one of them:

Each one of the ideas generated was evaluated in the five categories as low, average or high. A low evaluation scores one negative point for the idea, an average evaluation scores zero, and a high evaluation scores one positive point, as shown in Table 2. The criterion of price is an exception. A high evaluation scores one negative point and a low evaluation scores one positive point, as low price is a desired characteristic.

Each idea scored from five negative points up to five positive points, and, through a simple formula, this scoring was transformed into a value that varies from five to ten. Five is the minimum score given by the participation and ten is the score for an idea that best solves the problem 
addressed. The average of all scores is the final value that evaluates the quality of the method used.

\subsection{Presentation of the problem and dynamics}

The same text shown in Chart 1 was presented and read for each one of the groups.

After the briefing, which is identical in all surveys, and a fast conversation to clarify any doubt, the tool that should be used was briefly presented and explained to the group, as displayed in Table 3.

While Design Thinking has a more complex application and is characterized more as a thinking form than a simple set of rules, for the objectives of this research the explanation was enough and the results of the dynamics were satisfactory, i.e., the tools were made as mechanical as possible, as in a step by step guidebook, without entering into the merit of the objectives and concepts involved.

All meetings occurred with no huge surprises. In some cases clarifying simple questions was required, due to the non-familiarity of the participants with the tool tested, or even with the process of generating ideas. The suggested time was fully used in all the cases.

In the case of individual creation, it was preferred to perform the dynamics three times with distinct people, in order to not generate a bias due to the creating person, thus preventing the risk of choosing someone too much creative or very little creative.

\subsection{Results}

After the application of the dynamics, the proposals were evaluated and scored as defined in Tables 1 and 2 . Evidently, there is a degree of subjectivity in the evaluation made, even being performed by a professional of the area. It could be different if the evaluation was made by another expert. However, it is believed that, as an approximation, by evaluating proposals from professionals not related to the matter, no bias is incurred.

Table 4 illustrates how the criteria and the respective evaluations were listed. For the other cases, the same mechanics was followed. In the case of brainstorming, 29 ideas were generated, and through a simple average of scores for each idea, a value 8 was obtained for this tool.

Therefore, after completing the tabulation of all dynamics, Table 5 was built enabling the comparison among the diverse tools.

\section{Analysis of the results}

As it was said before - despite the subjectivism of the evaluations - it is possible to observe a confirmation of the theoretical expositions of the diverse authors, whether regarding the advantages, whether concerning the criticisms made.

Table 1. Criteria of evaluation of the tools.

\begin{tabular}{|l|l|}
\hline \multicolumn{1}{|c|}{ Criterion } & \multicolumn{1}{c|}{ Questions } \\
\hline Relevance & $\begin{array}{l}\text { Does the idea make sense for three to six years old children? Is the idea pertinent to Turma da Mônica's universe? Does } \\
\text { it fit inside an Easter egg or could it be given as an accompanying gift? }\end{array}$ \\
\hline Feasibility & $\begin{array}{l}\text { Taking the available resources and technologies into account (and ignoring at this moment the cost involved), it is } \\
\text { possible to manufacture the product? Is the product feasible? }\end{array}$ \\
\hline Desirability & $\begin{array}{l}\text { Would three to six years old children like to receive this product as a gift in an Easter egg? Children from both genders? } \\
\text { Does it have a secondary appeal to adults? }\end{array}$ \\
\hline Safety & $\begin{array}{l}\text { In a primary evaluation, does the product have any risk of generating small, spiky parts or any material that can cause } \\
\text { damage to the child's health? }\end{array}$ \\
\hline Price & $\begin{array}{l}\text { Taking the amount of materials, and assembly and painting operations into account, which is the estimated final price } \\
\text { of the product? }\end{array}$ \\
\hline
\end{tabular}

Table 2. Criteria scoring according to the evaluation.

\begin{tabular}{|l|c|c|c|c|c|}
\hline \multicolumn{1}{|c|}{ Evaluation } & Relevance & Feasibility & Desirability & Safety & Price \\
\hline Low & -1 & -1 & -1 & -1 & 0 \\
\hline Average & 0 & 0 & 0 & 1 & 0 \\
\hline High & 1 & 1 & 1 & 1 & -1 \\
\hline
\end{tabular}

Chart 1. Presentation of the problem or "briefing".

\begin{tabular}{|l|}
\hline \multicolumn{1}{|c|}{ SURVEY - EASTER - LICENSE:TURMA DA MÔNICA } \\
\hline BRIEFING: \\
Creating ideas of products to be distributed with Turma da Mônica's Easter eggs. The ideas must meet the following criteria: \\
- Low cost. \\
- They must please 3 to 6 years old boys and girls. \\
- They must be safe for all ages. \\
- Appeal to adults who have grown reading comic books is desirable.
\end{tabular}


Table 3. Instructions to the groups for each one of the tools analyzed.

\begin{tabular}{|c|c|c|c|}
\hline Methodology & Participants & Time period & Rules \\
\hline Brainwriting & 3 & $15 \mathrm{~min}$. & $\begin{array}{l}\text { - Talking is prohibited. } \\
\text { - Write the largest possible number of ideas in a sheet of paper. } \\
\text { - At this moment there are no bad ideas, everything is valid. } \\
\text { - After } 5 \text { minutes, exchange your sheet with another person and continue completing } \\
\text { the new list received with other ideas. } \\
\text { - Continues until all the sheets of paper are full of ideas. }\end{array}$ \\
\hline Brainstorming & 3 & $30 \mathrm{~min}$. & $\begin{array}{l}\text { - Invent the largest possible number of ideas together with your group. } \\
\text { - Do not criticize other's idea. The judgment of the ideas will be made later. } \\
\text { - Seek quantity and not quality. Choose someone to write down all the ideas. } \\
\text { - Talk about one idea at a time. }\end{array}$ \\
\hline Post-up & 3 & $30 \mathrm{~min}$. & $\begin{array}{l}\text { - Talking is prohibited. } \\
\text { - During } 10 \text { minutes, write each new idea in one post-it note. } \\
\text { - When the time is over, share and stick your and your colleagues' ideas on the wall. } \\
\text { - In group, select the similar ideas and organize the post-it notes by category or affinity, } \\
\text { creating a mental map. } \\
\text { - Add new ideas as they appear. }\end{array}$ \\
\hline Individual creation & 1 (3 times) & $20 \mathrm{~min}$. & $\begin{array}{l}\text { - Go to a private place where interruptions do not occur. } \\
\text { - With no external aid or interference, write the largest possible amount of ideas in } \\
\text { a sheet of paper. }\end{array}$ \\
\hline Design thinking & 3 & $45 \mathrm{~min}$. & $\begin{array}{l}\text { - The meeting is divided in } 3 \text { parts of } 15 \text { minutes each: } \\
\text { - IMMERSION: Talk to your group about the childhood universe, exploring its desires } \\
\text { during Easter and its relation to Turma da Mônica's stories and characters. Write } \\
\text { down everything in post-it notes and organize them on the wall with the comments } \\
\text { from other participants. } \\
\text { - DIVERGENCE: Write without critically evaluating all ideas of products that come } \\
\text { to mind, always consulting the post-it notes generated during the immersion. Write } \\
\text { down everything in post-it notes and organize them on the wall with the ideas from } \\
\text { other participants. } \\
\text { - CONVERGENCE: Evaluate with your group which are the best ideas generated } \\
\text { during the divergence phase, according to criteria presented in the briefing. Write } \\
\text { down the group's favorite ideas in a sheet of paper. }\end{array}$ \\
\hline
\end{tabular}

Analyzing Table 5, it can be seen that although in one of the cases individual creation has generated ideas with higher quality (with the highest score in the table), there is a distortion in the average caused by the extremely low amount of ideas (only five). Generally, individual creation generated few ideas (individually) and, therefore, less possible choices or starting points, reducing the probability of obtaining a real product at the end of the process. Comparing the average values of the groups that used specific methodologies to the averages of the individuals that created individually, the groups generated 31 ideas and each individual generated 7.3 ideas during similar time periods - on average, 30 minutes for the groups and 20 minutes for each individual. The quality evaluated for the groups received an average score of 8.0, while individual ideas had an average score of 8.4.

Considering that the groups were composed by 3 individuals, an average value per time period and resource would provide a better evaluation of the individual activity, i.e., the cost of the design professional would be lower for the individual modality. However, a reasonable amount of time was required in the preparation and the development of the dynamics, and not in the creative activity per se, in the case of the groups.

Regarding meeting the requirements and restrictions imposed to the product (Figure 1), it can be seen that there is a better absorption in the groups, whereas individually many of the restrictions are underestimated. The individuals brought creative ideas that in a second stage run a higher risk of being refused. This fact has lower occurrence in the performance in group, as instinctively the participants avoid solutions that could be denied by the own group later, i.e., the self-criticism eventually occurs, although the dynamics advise against it.

As a large amount of initial ideas is required, due to the volume produced and the size and diversity of the market, it seems more interesting in this specific case to use tools that provide this type of result. In addition, as the scores obtained in the evaluations are relatively close, it seems to be the most indicated criterion for the choice of a tool. In this situation, having a larger range of options is extremely desirable and creation tools in group clearly present an advantage. 
Table 4. Evaluation of the dynamics of brainstorming.

\begin{tabular}{|c|c|c|c|c|c|c|}
\hline Ideas & Relevance & Feasibility & Desirability & Safety & Price & Score \\
\hline Force measuring sledge hammer & -1 & 0 & -1 & 1 & 0 & 7.0 \\
\hline Mônica spinning Sansão & 1 & 0 & 1 & 0 & 1 & 8.0 \\
\hline Plush Sansão & 1 & 1 & 1 & 1 & 1 & 9.0 \\
\hline Small plush characters & 1 & 1 & 1 & 1 & 1 & 9.0 \\
\hline Key rings & 0 & 1 & -1 & -1 & 1 & 6.5 \\
\hline False tooth & 1 & 1 & -1 & 0 & 0 & 8.0 \\
\hline Mônica's dress & 0 & -1 & -1 & 1 & 1 & 6.5 \\
\hline Shoe & -1 & -1 & -1 & -1 & 1 & 5.0 \\
\hline Socks & -1 & -1 & -1 & 0 & -1 & 6.5 \\
\hline Pads & 0 & 1 & 0 & -1 & 1 & 7.0 \\
\hline Bop bag & 1 & 1 & 0 & 1 & 0 & 9.0 \\
\hline Kite & 1 & -1 & 1 & -1 & 0 & 7.5 \\
\hline Tic-tac-toe & 1 & 0 & 0 & 0 & -1 & 8.5 \\
\hline Briefcase & 1 & 1 & 1 & 1 & 0 & 9.5 \\
\hline Lunch box & 1 & 1 & 1 & 1 & 0 & 9.5 \\
\hline Mask & 0 & 1 & 0 & 1 & 1 & 8.0 \\
\hline Musical instruments & 1 & 0 & 1 & 1 & 1 & 8.5 \\
\hline Electronic Drum & 0 & 1 & 1 & 1 & 1 & 8.5 \\
\hline Catapult & -1 & 1 & -1 & -1 & -1 & 7.0 \\
\hline Pop-up pirate & -1 & 0 & 1 & 0 & 1 & 7.0 \\
\hline Soap box cart & 1 & -1 & 1 & -1 & 1 & 7.0 \\
\hline Turma's racing cars & 1 & 1 & 0 & 1 & 1 & 8.5 \\
\hline Notebook & 1 & 0 & 0 & 0 & 1 & 7.5 \\
\hline Spinning top & 1 & 1 & 0 & 0 & 0 & 8.5 \\
\hline Dolls & 1 & 1 & 1 & 1 & 0 & 9.5 \\
\hline Water shooter & 1 & 1 & 1 & 1 & 0 & 9.5 \\
\hline Glass & 1 & 1 & 0 & 1 & 0 & 9.0 \\
\hline Chauvinist Piggy Bank & 1 & 1 & 0 & 1 & 1 & 8.5 \\
\hline Eraser and pencil & 1 & 1 & 0 & -1 & 0 & 8.0 \\
\hline
\end{tabular}

Table 5. Summarized results of the dynamics.

\begin{tabular}{|l|c|c|c|}
\hline & Quantity & Quality & Time period \\
\hline Brainstorming & 29 & 8.0 & 30 minutes \\
\hline Brainwriting & 34 & 8.2 & 15 minutes \\
\hline Post-up & 29 & 7.7 & 30 minutes \\
\hline Design thinking & 32 & 8.0 & 45 minutes \\
\hline Individual creation 1 & 5 & 8.8 & 20 minutes \\
\hline Individual creation 2 & 11 & 8.0 & 20 minutes \\
\hline Individual creation 3 & 6 & 8.3 & 20 minutes \\
\hline
\end{tabular}

Disregarding the individual results and analyzing only the groups tested, in only 15 minutes, brainwriting tool generated 34 ideas, with a score of 8.2, largely superior in quantity per time, in relation to design thinking that generated 32 ideas in 45 minutes, and to brainstorming and post-up that generated 29 proposals in 30 minutes. Even so, brainwriting obtained a higher score than the other tools in group.

Brainwriting showed to be a mix between the individual creation - when the participants act without contact with the others - and in group - when the ideas are shared, and this seemed to be relevant in obtaining the results.

\section{Conclusion}

Considering these results, due to the high demand for innovation, it seems to be wise to use a combination of different tools during the process of creation of promotional products for Easter eggs. The alternation of the creative processes works as a form of mental training, providing each professional with different creative resources and preparing them to face the varied challenges that this market proposes.

Randomness has a pivotal role in some of the great discoveries of humanity, such as in Archimedes' Principle, the discovery of penicillin, and even in the random 
mutations that boost the mechanisms of evolution of the species. Analogously to the requirement for seeking the amount of ideas for the simple probabilistic increase of finding better ideas, knowing and being trained in a larger number of creative tools also increase the probability of finding winning ideas.

\section{References}

AMABILE, T. How to kill creativity. Boston, MA: Harvard Business, 1998.

Associação Brasileira da Indústria de Chocolates, Cacau, Amendoim, Balas e Derivados - ABICAB. Pesquisas e Estatísticas. 2014. Available from: <http://www.abicab. org.br/associado-chocolate-e-cacau/estatisticas/>. Access in: 22 Mar 2014.

Associação Brasileira de Normas Técnicas - ABNT. ABNT NBR NM 300-1 2004. Versão corrigida: 2011. Segurança de brinquedos - Parte 1: propriedades gerais, mecânicas e físicas. 2011. Available from: <http://www.abntcatalogo. com.br/norma.aspx?ID=87551>. Access in: 12 Apr. 2014.

BONO GROUP. Six hats presentation. 07:43 min. 2008. Available from: <http://www.debonogroup.com/video_4. php>. Access in: 09 Mar. 2014.

BOTTOM, A. The fear of saying something stupid (which stupid people never have) has censored far more good ideas than bad ones. Twitter. 2014. Available from: $<$ https:// twitter.com/alaindebotton/status/454003888342171648>. Access in: 09 Apr. 2014.

BROWN, T. Design thinking: uma metodologia poderosa para decretar o fim das velhas ideias. Rio de Janeiro: Elsevier, 2009.

BROWN, T. Tales of creativity and play. TED Talks. 2008. Available from: $<\mathrm{http}: / /$ www.ted.com/talks/tim_brown_on_ creativity_and_play.html>. Access in: 10 Feb. 2014.

CAIN, S. The rise of the new groupthink. The New York Times. 2012. Available from: <http://www.nytimes. com/2012/01/15/opinion/sunday/the-rise-of-the-newgroupthink.html>. Access in: 28 Jul. 2015.

Folha de São Paulo. Procon-RJ manda recolher ovo de Páscoa Bis Xtra + por incitar bullyng. 2014. Available from: <http://www1.folha.uol.com.br/ cotidiano/2014/04/1434755-procon-rj-manda-recolher-ovode-pascoa-bis-xtra--por-incitar-bullying.shtml >. Access in: 28 Jul. 2015.
GRAY, D.; BROWN, S.; MACANUFO, J. Gamestorming: jogos corporativos para mudar, inovar e quebrar regras. Rio de Janeiro: Alta Books, 2012.

HALVORSON, H. The key to being a creative leader? Job Security. 2013. Available from: <http://99u.com/ articles/7294/the-key-to-being-a-creative-leader-jobsecurity>. Access in: 28 Jul. 2015.

HUIZINGA, J. Homo ludens: o jogo como elemento da cultura. 5. ed. São Paulo: Perspectiva, 2001.

International Organization for Standardization - ISO. ISO 8124-1:2012: safety of toys - Part 1: safety aspects related to mechanical and physical properties. 2012. Available from: <http://www.iso.org/iso/home/store/catalogue_tc/ catalogue_detail.htm?csnumber $=62327>$. Access in: 12 Apr. 2014.

JOHANSSON, F. O efeito Medici: como realizar descobertas revolucionárias na interseção de ideias, conceitos e culturas. Rio de Janeiro: Best Seller, 2008.

LEHRER, J. Groupthink. The New Yorker. 2012a. Available from: <http://www.newyorker. com/reporting/2012/01/30/120130fa_fact_ lehrer?currentPage=all> . Access in: 08 Mar. 2014.

LEHRER, J. Imagine: how creativity works. Boston: Houghton Mifflin Harcourt, 2012b.

NUSSBAUM, B. Design thinking is a failed experiment. So what's next? Fast Company. 2011. Available from: $<$ http:// www.fastcodesign.com/1663558/design-thinking-is-afailed-experiment-so-whats-next>. Access in: 06 Apr. 2014.

PRADO, L. Páscoa 2014 - mercado deve oferecer 80 milhões de ovos. Clube de Criação de São Paulo. 2014. Available from: <http://www.ccsp.com.br/site/ultimas/67886/ Pascoa-2014/>. Access in: 22 Mar. 2014.

PUCCIO, G. Creativity as a life skill: Gerard Puccio at TEDxGramercy. TED Talks. 2013. Available from: $<$ http:// tedxtalks.ted.com/video/Creativity-as-a-Life-Skill-Gera>. Access in: 15 Mar. 2014.

TJENDRA, J. Why design thinking will fail. Business Innovation Design. 2014. Available from: <http:// businessinnovationbydesign.com/blog/2014/3/23/whydesign-thinking-will-fail>. Access in: 28 Jul. 2015. 